The original version of this article appeared in Journal of Mass Media Ethics 20:2\&3 (Fall 2005), p. 159-175. The original version may be accessed at http://www.tandf.co.uk/journals/default.asp.

\title{
Cyber Citizen or Cyborg Citizen: Baudrillard, Political Agency, and the Commons in Virtual Politics
}

\section{Introduction}

With the growth in the popularity and power of internet technology over the last twenty years there have been increasing calls for the use of internet technology in political life. Such calls have generally been of two types. First, there is the claim that the internet can be used to enhance citizen access to information and government services. Such programs are active in some cities in the United States, such as Santa Monica, California. Globally, the use of the internet in service delivery also can be found in Holland, Greece, and Italy.

The other claim regarding the internet's potential promotes the use of the technology to "enhance" the processes of democratic practice. Information age optimists such as Daniel Bell (1973), Alvin Toffler (1980), and Benjamin Barber (1984), asserted the potential of the internet to expand democratic participation and reinvigorate the petrified institutions of democratic practice that increasing find their legitimacy called into question. Trends indicate that such usage is growing. For example, in the 2000 United State presidential race the internet was used in the Arizona primary, and in the state of Washington. In the 2004 presidential campaign Howard Dean used the internet to mount a grass-roots fund raising campaign in his bid for the Democratic Party's nomination. Both the Bush and Kerry campaigns replicated the success of the Dean 
strategy. However, the internet has also been used in other political contexts. In Greece and Germany it is used as a forum for public political discourse. Discussions have begun in Great Britain about moving to full internet voting within a decade.

As the industrial societies move ahead with the use of this information technology the are two critical questions that must be answered. Will the use of this technology extend or damage the Western Industrial society's ethical commitment to democratic practice? Democratic political practice is premised on the principle of an informed citizenry engaging in a public discourse about the collective decisions of society. Implicit in the commitment to democracy, therefore, is a belief in the rational capacities of the public and the right of the public to exercise that reasoning ability in a meaningful way. Secondly, will the use of the internet, and the engagement of virtual space, translate into the protection of the real space in which human interaction takes place? Implicit in the normative defense of democracy is the position that there must be a public arena, a political space, in which debate and discussion can occur.

This paper will give a critical appraisal of the internet's effects on two principles of democratic practice. First, it will be argued that the way in which the internet has entered the arena of politics has undermines the notion of rational agency. Most political communication on the internet, whether from the right or left side of the political spectrum, takes place in a one-way environment. It will be argued that such a practice reinforces the passivity of political agents, undermining the conditions for democratic politics.

The paper's second critical claim is that in developing and supporting a "virtual" space for political discourse, the internet has the potential to dilute the commitment to 
"real” political space for democratic processes. The internet is a conduit for information. However, while information is a necessary component for democratic practice, it is not a sufficient condition for democracy. Democracy is an activity. The critical question when considering the role of the internet in democratic societies is whether or not it enhances the processes and activities of democratic practice. To the extent that the internet obscures or even supplants the existence of public space with virtual space, it undermines a condition necessary for democratic practice. Democracy requires real space, for real bodies. Public space, or idea of the "commons," has served as one of the foundation of democratic practice since the time of Greek democracy. Virtual space, as a space of democratic participation, is simply not analogous to the commons.

In order to develop the concern about political agency, this work will begin with a discussion of Jean Baudrillard. Baudrillard represents one of the most important critics of the cyberspace and the virtual world. Baudrillard claimed that our conception of ourselves is altered by our contact with the instruments of virtual reality. Hence, he is very important for understanding the impact of technology on the idea of political agency. From there the paper will discuss three models of human agency: the passive agent, the rational actor, and the citizen sovereign. It will be argued that the internet actually reinforces elements of the first two, but that it is structurally ill-equipped to promote the third. From there the paper will proceed into a discussion of the internet and the idea of the political commons. It will be argued that the virtual space of the internet does not correspond to real political space, democratic practice, or promote the idea of the commons. 
The paper will conclude by stating that the development of internet technology constitutes a challenge to contemporary society's commitment to the ethics of democratic practice. To the extent that the internet is used as a one-way means of public indoctrination it fails to enhance the norms of democratic practice. Further, if the internet only serves to enhance information flow and exchange in virtual space, it fails to protect the real space of democratic practice. To this degree the use of the internet in political practice must be seen as potentially dangerous to the underlying values of democracy.

\section{Baudrillard and the Critique of Virtual Politics}

In the late Twentieth Century the French philosopher Jean Baudrillard has written extensively on the topic of technology, media, culture, among other interests. As such, he is an important figure in shaping the discussion about the effects that the new technologies have on human beings and on political practice. Baudrillard's writings represent a synthesis of Marshall McLuhan’s work on media, Max Weber’s (1958) concerns about Enlightenment rationality, leftist politics, and postmodern epistemology.

To put it mildly, Baudrillard is pessimistic about the uses to which the new information technologies are being put. For Baudrillard, information technology represents a medium that diminishes the value of human subjectivity itself. Meaning is lost within the network of communications. Deliberation is replaced by immediacy. The "real" is replaced by simulation. Reality is being "murdered" by the process of rationalization and the virtual world (Baudrillard, 2000, p. 164). 
In this context, political life is not just altered, it is destroyed. Political life, which was characterized by the drama of subjects struggling against the alienating components of economic and political repression, now disappears in a digitized universe. In contrast to McLuhan (1989), the medium does not create the global village, but the isolated and alienated subject, a subject now cut off from the public space needed for real political interaction. Using the internet as a medium of politics furthers the process of estrangement in social life by neutralizes the potentials of political interaction.

To Baudrillard, our contemporary age is characterized by simulation. Simulation represents a fabrication of the "real" without reference to an origin. To put it another way, the project of simulation is to make the real conform to that which is fabrication (Baudrillard, 2000, p. 2). Simulation represents a condition in which the measure of truth, meaning, and value are validated by their correspondence to the prevailing model in which they are constructed (Baudrillard, 2000, p. 32). Today we live in a hallucination of the real (Baudrillard, 2000, p. 148). Discourse on the metaphysics of being has given way to the metaphysics of the "code," a projection of an "objective” form of knowledge. As Baudrillard described this process, the Jesuit drive for unity and certainty has returned to us in the postmodern era in the form of mapping DNA, a task designed to remove any ambiguity about human nature.

To understand the significance what Baudrillard means by simulation it is important to remember that to the poststrucuturalists in general, truth, value and meaning are historical constructions. Therefore, technology and communications play a significant part in the construction and significance of the sign. This means that the mechanisms employed in the process of transmitting signs, value, and meaning 
circumscribe the limits of what can and cannot be transmitted. Quoting McLuhan, Baudrillard repeated that the "medium is the message" (2000, p. 124).

The medium today is electronic communication, particularly the internet. The internet is a digitized medium, characterized by binary code. Baudrillard's claim is that there is a parallel process taking place on a cultural level in which the entire realm of social interaction is entering a phase in which the binary code of the computer is being replicated within the forms of human interaction. Today we have the "mystic elegance of the binary system, of the zero and the one, from which all being proceeds” (Baudrillard, 2000, p. 106). Human contact is being replaced by a digitized realm in which only that which can lend itself to digitization can be considered as the proper content of communications. This means that political interaction increasing takes the form of a choice among binary opposites.

\section{Technology and Cyborg-Citizenship}

Baudrillard asserted that today the real has been murdered by the process of rationalization and the virtual world (Baudrillard, 2000, p. 64). The significance of this notion for politics cannot be overstated. While Baudrillard claimed all three orders of appearance are means of control, he focused most of his concern on the plight of freedom within the process of simulation. Baudrillard saw the political process within the Enlightenment as dominated by a particular drama, as the masses struggled against forces that sought to alienate or oppress them. The Enlightenment conception of reason was the tool of liberation, as reason was to enlighten a superstitious mass to the understanding 
that their acquiescence is what allowed despots to live (Baudrillard, 1988a, p. 217). Today we are no longer subject or object, alienated or free. This is the case because today the alienation of man by man is a thing of the past (Baudrillard, 1993, p. 58-59). Today we are alienated by machines and the code.

The "telecomputer man" of the contemporary age is not aware of the condition of his own servitude (Baudrillard, 1993, p. 59). We have been integrated into the machines of communications (Baudrillard, 1993, p. 58). This “prosthesis” displays the spectacle of thought, but is incapable of displaying thought itself (Baudrillard, 1993, p. 51-52). Freedom is manifested as freedom for virtual interaction rather than real social and political action (Baudrillard, 1994a, p. 30).

The result of this digitized interaction of screens rather than people is that real political interaction is dead (Baudrillard, 1993, p. 41). Today the value of a political message is not in its meaning but in its circulation. The idea of human agency, of subjects acting in the world, is replaced by a new metaphor. Human beings now become sending and receiving "satellites" connected in webs of networks, in which being connected and transmitting information becomes an ontological end in itself, a new means of gratification (Baudrillard, 1988b).

This new means of gratification is satisfied by an orgy of superfluous information. Baudrillard called this the new form of obscenity (1988b, p. 24). Within this context the idea of meaningful public space is disappearing. All is transparent, but all is on the surface. There is no depth and no meaning (Baudrillard, 1988b, p. 12). The use of binary coding for the transmission of information alters the content in order to fit the technology. With binary coding the symbolic dimension of language is lost (Baudrillard, 
2000, p. 69). Politics, as a struggle to overcome the condition of alienation and oppression takes on the character of a simulation. Virtual liberation masks the continued expansion of the instruments of oppression. In the transpolitical world that is created the political game becomes that of seduction (Baudrillard, 1988b, p. 59).

The simulation of politics is coupled with a de-ideologicalization of the masses (Baudrillard, 1993, p. 41). However, Baudrillard did not view this as a positive development. In the place of ideology, Baudrillard saw the public opinion poll. The process of opinion polling sits at the nexus of several of Baudrillard's comments about the political. The opinion poll is part of the orgy of information that obfuscates the struggle against oppression. It covers up the real structure of oppression, as the public does not really form independent, or transcendent, positions anyway. It is Baudrillard's opinion that the opinions of the masses are responses shaped by cues received from the political class and from a prepackaged corporate media structure that does not allow space for the construction of an independently formed opinion (1983, p. 131; 1993, p. 41). The real effect of the concept of "public opinion" is the neutralization of class antagonisms. It seeks to substitute the idea of a single outcome, a united path, among competing and antagonistic groups.

The de-ideologized mass now becomes "prey to probability theory" (Baudrillard, 1993, p. 41). Opinion polling and statistical analysis now produce the "truths" for a simulated politics. There can be no rational dissent, as “objective data,” probability theory, rational choice ontology, and the expansion of consumerism, now establish the singular path to the future. The unity of humankind is established. All are the same. The power of seduction is that to think differently is to be labeled as "irrational." 
From this perspective, the introduction of the internet into the political realm does not open up new arenas of public space. Baudrillard's contention was that public space is disappearing, as the virtual space of the web is not real public space (1988b, p. 19). Within this framework, the politics on the web is part of the erosion of the political. Political parties represent the compulsion of the game, organizations designed to extend the influence of power. The emergent simulation of the democratic process requires more than one party, as debate between two subgroups of the political class can create the illusion of legitimacy. For this reason, claimed Baudrillard, political parties position themselves in a way that renders a 50/50 split in the voters so the results of elections are simply the product of chance (1983, p. 132). Election results do not result in major changes anyway, since both political factions tend to represent the conditioning of the corporate interests and the political class as reflected in the media. The internet is simply one more medium, one more tool for the organization and control of the masses.

In order for Baudrillard to draw this type of conclusion he rejected the idea that media, in general, are mechanisms that further the notions of either rational or sovereign actors. The masses are simply passive agents of manipulation, mesmerized and seduced by the illusion of politic choices that appear to them on voting day, whether that voting is to take place in a both at a fixed location or via the web in cyberspace. Whether represented by the Green Party's virtual party congress in Baden-Würtemberg, the Pericles project in Athens, the Arizona primary in 2000, or the Kerry and Bush campaigns in 2004, all extend the conformity of the dominant ontological model of consumption and expansion. 
From this perspective, the internet does not create open space in which citizen sovereigns can reassert the democratic values contained in the Enlightenment ideal. Instead, extending a virtual form of democratic practice on the internet creates a simulation of a democracy within the commons.

IV. Agency and the Idea of the Commons

Baudrillard's critique of political practice within the present conditions of information culture raises concerns in two areas critical for democratic practice. The process of simulation cannot be divorced from the technological means that engender it. Simulation is not the real, as the virtual is not the actual. Therefore, claims that the internet represents the new public space for political discourse, a new technological commons, are overstated.

In addition, Baudrillard raised the issue of human agency in claiming that the content of human subjectivity is altered by the interaction with the technology itself. At the very foundation of democratic practice is the idea that the demos is capable of making rational decisions when confronted with problems. However, the question remains. What model of human agency is reinforced by the internet politics?

A. Technology, Politics, and Three Models of Human Agency

In the few cases where political agency is discussed at all, information technology is usually applauded as providing a liberating potential. As stated by Anna Sampaio and 
Janis Aragon, cyberspace is a place of anonymity, a place where the traditional markers of hierarchy, such as age, sex, and race no longer are tagged to human subjectivity (Sampaio and Aragon, p. 153). One is free to enter a chat room and take on any identity one wishes. Without hierarchy and the symbolic tags of human identity, cyberspace is a place where reason can have its domain. It is a place of democratic potential, as a public sphere designed for interactivity and participation. As Juliet Roper described it, cyberspace can provide the Habermasian space for communicative action, free from the influences of domination and subordination (Roper, p. 69). From this perspective, the new technology can be used to expand participation in the Western democracies. The internet constitutes a new public space in which the citizenry can become informed and organized for rational political activity.

However, to fully understand these changes it is necessary to make one assumption; human nature is not static. To put it more directly, there is no such thing as "human nature," defined as essential traits to the human personality. In the contact with the various forms of information technology, the behavior, norms, and self-understanding of human subjectivity become altered. Following the claims of Marshall McLuhan (1962) (and a position adopted by Jean Baudrillard) it will be asserted here that the human subject is altered by the conditions of communications technology. The new information technologies cannot be seen as simply being adapted to a static conception of subjectivity, but are themselves part of a cultural milieu that, in turn, shapes the parameters of thought, and the expectations of collective action.

What was true in former times is no longer true. Today, speed and accessibility to avenues provided by information technology have produced a glut of data and opinion. 
We suffer from what Baudrillard refered to as an "obscenity" of information, an information overload. However, what McLuhan suggested is still true. Subjectivity is continually reconstructed out of our association with the medium. This association establishes sets of norms, limits, and material available for transmission. We alter our expectations and our understanding of ourselves, our political efficacy, and our political practices in the process. Therefore, it is important to understand the form of subjectivity that is reinforced by our association with the medium, regardless of its specific content. Three such models of interaction can be identified.

\section{Passive Agent}

To the extent that human interaction with information technology constitutes a one-way flow of information from a person, group, or commercial interest, to the viewer of web material, the model of subjectivity that is being reinforced is that of passive agent. In this usage the viewer may be seeking information, or may be solicited by the person or organization possessing the viewed material. In either case, however, the viewer is engaged with the material as a passive agent, not interacting, or engaging in any discourse with the material, beyond possibly clicking from one subsection to another. In this role, the internet simply has the character of any other mechanism for mass communications. It hosts the display of prepackaged material, without the possibility of active engagement on the part of the web viewer.

This model has been predominate in the commercialization of the web, but has also been adopted by organized political groups, activist organizations, political parties, and government entities. In this usage the internet takes on the character of a 
sophisticated billboard for advertising purposes. In political terms, this usage has been undertaken by political parties in most of the industrial democracies, as well as government itself. Examples of government's use of this model can be found in American cities, including the California cities of Glendale, Pasadena, and Santa Monica. However, this model is not what Habermas (1984) had in mind as expanding the public sphere. As Oliver Schmidtke put it, the internet provides the perfect public relations tool for government, as it can disseminate information to rationalize all of its policies (Schmidtke, p. 67). In terms of usage, this model is the most consistent with topdown hierarchical control, and has the effect of reinforcing group identity, without regard for bottom-up political influence.

\section{Rational Actor}

If the passive agent model can be said to raise concerns about the continuation of hierarchy and control, it is the rational actor model to which optimist point as carrying the potential for a new form of civil democracy. Here the model of exchange replaces that of passive consumption. Individuals can seek special information, organize chat-rooms, interest groups, email lists, all with a very low cost in terms of financial resources (Resnick, p. 64). In this usage the net resembles a pluralistic civil society, egalitarian in terms of each participants voice having the same potential, where only the stronger argument will prevail. For this reason, Douglas Kellner stressed the importance of resistance groups organizing via the web to counteract the established economic interests seeking to subjugate the populous (Kellner, p. 173). 
However, this raises an interesting question with regard to the web and its content. On this level, the web lends itself equally well to agents of change on both the left and the right of the political spectrum. It is a medium of discourse for both anarchists and fascists. Therefore, regarding political ideology and the internet, it is necessary to conclude that the web contains no implicit normative bias towards the principles of democratic pluralism.

What can be claimed is that the internet, used in this mode, has a conditioning influence on subjectivity. Here the internet reinforces the Enlightenment ideal of an individual rational subject seeking to grasp the objective environment as part of his or her life experience. As Tim Jordon described it, from this perspective cyberspace is a "place where individuals can finally rest control of their being from institutions, governments, corporations, and oppressions” (1999, p. 96). However, since the internet contains no necessary normative claims with regard to community, and since it reinforces an individualistic conception of subjectivity, some scholars have concluded that the political outcome of the web’s influence on human subjectivity will be one of political fragmentation (Schmidkte, p. 61).

The rational actor is motivated by the calculation of rational self-interest. The zenith of the rational actor model is found in the commercialization of the internet. One seeks to maximize self-interest though finding "the best deal," and the internet is exceptionally useful for this task. However, the medium does not necessitate a public or community concern. Democracy cannot be measured by being able to exercise reason though shopping. 


\section{Sovereign Actor}

The sovereign actor model, in its ideal form, seeks to carry the rational actor model to its political conclusion. As a sovereign actor, the individual approaches the internet both as a medium of information and as a venue for expressing a voice in binding collective decisions for some administrative unit. In this model the web is a place for engaging in democratic activity. This may take the form of direct or plebiscite democracy. This is regarded by some to be the means by which to overcome the apathy and cynicism increasingly found in the Western democracies.

While yet to be fully implemented in this form, there have been a variety of experiments tilting in this direction. In Athens, the Pericles project was launched in 1992 (Tsagarousianou, 1998). Started by a group of intellectuals and scientist, "Network Pericles” as it is know set up terminal in Athens at which citizens could raise issues, gather information, and express their opinions by voting. While the results are not binding, and constitute more of an ongoing public poll, the framework is one that could be used as a model for expressing collective decisions. Experiments are taking place in other European cities such as Amsterdam, Manchester, and Bologna. In the United States 2000 presidential primaries, citizens of the state of Arizona were able to cast their votes on-line. It is in this direction that the 2000 party meeting of the Greens in BadenWürtemberg also moved. Delegates were able to raise issue, engage in an exchange of ideas, and then cast binding votes for the party.

Critics of the sovereign actor model generally raise several concerns. First, there is the issue of access. Will this be democratic if all people do not have an internet connection? A further concern was voiced by Jeffrey Abramson, et. al., in the work The 
Electronic Commonwealth. In this work the authors argued that plebiscitary democracy is not really deliberation, but just another form of polling (Abramson, Arterton, \& Offen, 1988). Since plebiscites are personal and private, such activity does not expand democracy as an activity in the commons. In fact, using the internet to carry out a seemingly democratic practice such as a plebiscite can have the effect of further isolating human political agency (Dijk, 2000).

Regarding the web’s impact on human subjectivity a more complex paradox emerges. Even if one adopts the Enlightenment model of the rational subject, it would seem that features of the internet inhibit the revitalization of community and democracy. As discussed in the previous section, the specialized information that can be provided on the web does not require allegiance to the local institutional authority. Because the web has no territoriality the notion of national community is not reinforced as part of socialization process on the web. All exists as a simultaneous presence. To put it another way, there is no necessary reason to engage in a relegitimation of the nation-states or communities. The extra-territorial nature of the internet does not reinforce the normative components of territorial administration. From this perspective the nation-state is nothing but nostalgic fiction (Angell, 1996; Ohmae, 1995). As Kenichi Ohmae claimed, the nation-state is reduced to a protection racket designed to protect the biggest racketeers (p. $64)$.

B. The Political Ethics of the "Commons" 
The idea of the "commons" is a central component of democratic practice. In his essay "Structural Transformations of the Public Sphere” John Keane described the notion of a public sphere as an early modern idea to designate an arena of action protected from arbitrary government power (2000, p. 70). In his writings Keane argued that the idea of a public sphere needs to be rethought in order to include the internet.

A similar sentiment is echoed by Peter Levine in his work "Civic Renewal and the Commons of Cyberspace.” Levine argued that the idea of the commons is a shared property managed by the people. The internet satisfies this requirement because no one owns it and its open architecture allows it to be a source of information to the citizens of a nation (Levine, 2001, p. 205-213). However, Levine cited a Stanford University study that suggests when people are exposed to the internet they are turned into passive users, spending less time with friends and family.

Does the internet qualify as an extension of the "commons"? In order to answer such a question it is necessary to explore two further questions. First, is it possible to translate the activities of the virtual space found on the internet to the real space of public interaction? Second, does the interaction of the subject with the medium promote public interaction and the open exchange of ideas, conditions that would enhance the volume of democratic activity? The answer to both questions is no.

To be successful as a medium that promotes democratic politics certain conditions must be present. The internet must provide quality information (information that is factually correct), without a sufficient degree of bias. It must be a medium in which there is the possibility of real exchange and inquiry. The material must be subject to both interrogation and debate. Third, the material must be in a context that reinforces political 
activity in the public sphere. Democracy is an issue of public space and material bodies in that space.

\section{Information}

Technology has always produced changes in the cultural forms of subjectivity. With the construction of the first printing press the world underwent a transformation. From the work of scribes taking years to copy a single text, mass quantities of a work could be produced and disseminated in a relatively short period of time. This material transformation in the cultural conditions of life allowed for the production of both higher volume and more varied works than previous ages. Such a change produced the need for new texts. The subject, as the author of words, was born.

With the internet, the potential exists not just for everyone to be an author, but for subjectivity to be expanded into the realm of production itself. The internet produces a condition in which everyone who has access can also be a publisher. The result, to paraphrase Jean Baudrillard, is an "orgy" of information, with a quantity and variety that is impossible to digest.

Such a claim was made by David Shenk, in his book Data Smog (1997). Shenk argued that the internet floods people with so much information that it is impossible to sort the legitimate from the illegitimate information. In such a condition democracy is not enhanced. Shenk claimed that giving more power to people who are misinformed actually constitutes a danger to democratic to democratic norms and values. As Cass Sunstein (2000) described the problem in Republic.Com, the internet allows one to close 
themselves off from the public sphere and seek out those views that simply reinforce preexisting biases. Democracy is simply not something that can be practiced in isolation.

There is a further problem when it comes to information. Even if the idea of "unbiased" information is discounted, there is a problem with the material generated in an internet search. With the colonization of the internet by corporations, both as portal access points and as information and commodity providers, the influence of economic interests has grown significantly. Even when it comes to information, it is managed by corporate interest that may pay to have search engines retrieve their own data over that of others. Users are steered to the websites determined by the service providers who receives fees from corporate advertisers (Levine, 2001, p. 205-213).

\section{Exchange}

In the Platonic Dialogue called the Phaedrus (1989) Socrates criticized the art of writing as a tool of political life. Writing, he claimed, like speech giving, creates a dead artifact. It cannot be explored, questioned, or interrogated. It is a form of mass political indoctrination, not political discourse. While Socrates did not support democratic politics, he outlined the conditions necessary for democratic practice.

The idea that the internet can promote the model of citizen sovereignty is dependent upon the idea of exchange. It must be possible for large groups of people to express their views in a forum in which their ideas can be examined and weighed against other ideas and policy options. The idea of the commons as a place of open exchange is essential for the practice of democratic politics. 
However, public debate is not really possible on the internet. The places where discussion and debate may take place are in "chat rooms," but these are limited in size and scope. AOL limits participation in chat rooms to twenty-six members (Levine, 2001, p. 208). Such a small group cannot extend democratic sovereignty. Commercial media outlets often take polls of public sentiment, but such an activity does not constitute the debate and discussion necessary to democratic practice.

\section{Political Activity and Public Space}

Democracy is an activity. It takes place in a public domain where citizens come together to make choices about real policy options. The citizen sovereign model of human agency is reinforced by that activity.

Information is material for the process of decision making, but it is not a substitute for it. Under conditions of democratic practice it is presumed that better outcomes will result when better information is distributed to the widest possible audience of citizens. However, discourse and deliberation, the practice of democracy, always takes place with less than perfect knowledge. Therefore, information is not a substitute for the practice of open exchange in a public forum.

There is a great deal of misunderstanding about the virtual space created on the web. Proponents of internet politics point to the space created on the internet and claim that it constitutes a new sphere of public space. However, the claims that the internet constitutes public space for real human agents ignores the reality of the internet. The internet provides virtual space. It can be wide open because it is neither real nor public. The internet is better suited to private activity. The paradox of the internet is that while it 
may be a place where one can practice freedom in virtual reality, when one leaves the machine one returns to whatever form of oppression suffered in the real world of embodied selves.

The promise is that a virtual body can operate outside the limitations of space and time. It can allow for the construction of a body not tied to the prejudices of race, gender, age, or physical attributes. But what does it mean when we disconnect the real self, who is a member of social class, race, gender, and all the trappings of material being in favor of the virtual self? Disconnecting the body from the physical experience of life prevents the political agent from acting to secure political rights within the confines of the physical space in which real agency acts. The body has material needs that must be met. Class, gender, race, age, and physical attributes may produce conditions of oppression in the real activities in which people engage in their daily lives. It may be that the construction of a virtual self on the internet constitutes a seductive new opiate consumed in order to escape the real conditions of oppression.

The virtual self is not flesh and blood, but has been reduced to data within the binary code of the computer. It is a further means of objectification, the reduction of human beings to shopping preferences, web visitation schedules, library usage, and medical maladies. Within this framework, the codified self becomes the reality. Once the subject is reduced to data, we are simply objects of control and manipulation for police surveillance and corporate tracking.

Conclusion: Cyborg Citizens and the Internet 
The point of this essay was not to suggest that we should dismiss the internet as a tool of communications technology. It has the potential to provide instantaneous access to vast quantities of information. As a storage and retrieval mechanism for data of all sorts it is a revolutionary advance in human technology.

However, while information is a necessary component of democracy it should not be considered the only component of democratic practice. Therefore, it is imperative that the potential dangers for democratic norms and values resulting from the new technologies also be considered. The ethics of democracy represent a commitment to the notion that rational beings can govern themselves. This requires an active citizenry engaged in a discourse about the challenges that confront them. It is illusory to believe that the internet represents the public space for such deliberations.

This paper has sought to argue that it is a mistake to claim that the internet only serves to enhance democratic participation. The internet is largely a medium of one way communication, on the order of a super-television where there are millions rather than hundreds of channels. In such an environment, a person can receive the political indoctrination of his or her choosing. However, one watches rather than participates. Further, the space of this interaction is virtual, not real space. Virtual identity is not real identity. Virtual democracy is not the exchange of ideas, a discourse on policy, or real engagement. Polling is not democratic participation.

Virtual politics is not the answer to a public that is increasingly disenfranchised, cynical, and alienated from real political engagement. In the end virtual politics is likely to heighten such feelings. Without a population committed to democratic values, internet politics could produce a future in which overlords artificially contrived choices for a 
public whose opinion has already been shaped by the conditions of their own oppression. Hence the danger of internet politics is in its use as a new form of mass dissemination, along with the other technologies of mass administration used in the Twentieth Century. In that regard, it could simply become another technology of control.

To confront the dangers to democratic practice one must be aware of them. These dangers run far deeper than simply the concerns over the use of technology for surveillance. We are condition by the technology itself. Unless we are aware of this conditioning we face the possibility of democracy becoming anachronistic, overwhelmed by the sheer weight of mass culture and mass institutions. 


\section{References}

Angell, I. (1996). Winners and Losers in the Information Age. Culture and Society, vol. 34:1, 81-85.

Abramson, J., Arterton, C., \& Offen, G. (1988). The Electronic Commonwealth: The Impact of New Media Tehnologies on Democratic Politics. New York: Basic Books.

Barber, B. (1984). Strong Democracy: Participation Politics for a New Age. Berkeley: University of California Press.

Baudrillard, J. (1983). Simulations. New York: Semiotext.

Baudrillard, J. (1988a). Selected Writings. Poster, M. (Ed.), Stanford: Stanford University Press.

Baudrillard, J. (1988b). The Ecstasy of Communication. New York: Semiotext.

Baudrillard, J. (1994a). The Illusion of the End. Stanford: Stanford University Press.

Baudrillard, J. (1994b). Simulacra and Simulation. Ann Arbor: University of Michigan Press.

Baudrillard, J. (1993). The Transparency of Evil. London: Verso Press.

Baudrillard, J. (2000). The Vital Illusion. New York: Columbia University Press.

Bell, D. (1973). The Coming of Post Industrial Society. New York: Basic Books.

Davis, R. (1999). The Web of Politics. Oxford: Oxford University Press.

Derrida, J. (1981). Dissemination. Chicago: University of Chicago Press.

Dijk, Jan van. (2000) "Models of Democracy and Concepts of Communication,” in Digital Democracy: Issues of Theory and Practice. Edited by Kenneth Hacker and Jan van Dijk. London: Sage, 30-50.

Habermas, J. (1984). The Theory of Communicative Action, Volume 1. Boston: Beacon Press.

Hacker, K., \& Dijk, J. (Eds.). (2000) Digital Democracy: Issues of Theory and Practice. London: Sage.

Hill, K.A., \& Hughes, J. (1998). Cyberpolitics. New York: Rowman and Littlefield. 
Jordon, T. (1999). Cyberpower. London: Routledge.

Keane, John. (2000) "Structural Transformations of the Public Sphere," in Digital Democracy. Edited by Kenneth Hacker and Jan van Dijk. London: Sage, 70-81.

Kellner, Douglas. (1998) "Intellectuals, the New Public Sphere, and Technopolitics" in The Politics of Cyberspace, edited by C. Toulouse and T. W. Luke, New York: Routledge, 167-186.

Levine, P. (2001, Fall) "Civic Renewal and the Commons of Cyberspace.” National Civic Review, 90:3, 205-213.

Luhmann, N. (1990). Essays on Self-Reference. New York: Columbia University Press.

Margolis, M., \& Resnick, D. (2000). Politics as Usual: The Cyberspace Revolution. Thousand Oaks: Sage.

McLuhan, M. (1962). The Gutenberg Galaxy: The Making of Typographical Man. Toronto: University of Toronto Press.

McLuhan, M. and Bruce Powers. (1989) The Global Village. New York: Oxford University Press.

Ohmae, K. (1995). The End of the Nation State: The Rise of Regional Economics. New York: Free Press.

Plato. (1989) "Phaedrus," in Plato: The Collected Dialogues, edited by Edith Hamilton and Huntington Cairns, Princeton: Princeton University Press.

Resnick, David. (1998) "Politics on the Internet: The Normalization of Cyberspace," in The Politics of Cyberspace, edited by C. Toulouse and T. W. Luke, New York: Routledge, 48-68.

Roper, Juliet (1998). "New Zealand's Political Parties Online,” in The Politics of Cyberspace, edited by C. Toulouse and T. W. Luke, New York: Routledge, 69-83.

Sampaio, Anna, and Janis Aragon (1998). "To Boldly Go Where No Man has Gone Before: Women and Politics in Cyberspace," in The Politics of Cyberspace, edited by C. Toulouse and T. W. Luke, New York: Routledge, 144-166.

Schmidkte, Oliver. (1998). "Berlin in the Net: Prospects for Cyberdemocracy from above and Below," in Cyberdemocracy: Technology, Cities, and Civic Networks, edited by Roza Tsagarousianou, Damian Tambini, and Cathy Bryan, New York: Routledge, 60-83.

Shenk, D. (1997). Data Smog: Surviving the Information Glut. New York: HarperCollins. 
Sunstein, C. (2000). Republic.Com. Princeton: Princeton University Press.

Toffler, A. (1980). The Third Wave. New York: Morrow.

Toulouse, C., \& Luke, T.W. (1998). The Politics of Cyberspace. New York: Routledge.

Tsagarousianou, R. (1998) "Back to the Future of Democracy,” in Cyberdemocracy:

Technology, Cities, and Civic Networks. Edited by R. Tsagarousianou, D. Tambini, and C. Bryan. London: Routledge, 41-59.

Tsagarousianou, R., Tambini, D., \& Bryan, C. (1998). Cyberdemocracy: Technology, Cities, and Civic Networks. London: Routledge.

Weber, Max. (1958) The Protestant Ethic and the Spirit of Capitalism. New York: Charles Scribner.

Wilhelm, A. (2000). Democracy in the Digital Age. New York: Routledge 